\title{
The genesis of supported cobalt catalysts
}

\author{
Fiona A. Wigzell ${ }^{1} \cdot$ S. David Jackson ${ }^{1}$ (I)
}

Received: 10 May 2016/Accepted: 6 December 2016/Published online: 10 December 2016

(c) The Author(s) 2016. This article is published with open access at Springerlink.com

\begin{abstract}
The general objectives of this research were to investigate the effect of the support and the gas atmosphere on the decomposition and reduction of cobalt nitrate hexahydrate supported on silica and alumina to gain a greater understanding of the calcination and reduction procedures used in catalyst manufacturing processes. The decomposition was followed by TGA-DSC-MS. The observed breakdown on the unsupported complex is similar but not identical to previous reports with NO detected as an evolved gas. In an oxygen/argon atmosphere the decomposition is generally simplified for the supported samples with a fewer number of weight loss events. When supported on alumina, cobalt nitrate is stabilised with decomposition events shifting to higher temperatures, whereas when supported on silica, cobalt nitrate is destabilised with only one significant decomposition event, which occurs at a lower temperature than that of the unsupported complex. In a hydrogen/nitrogen atmosphere partial decomposition of cobalt nitrate occurs before reduction is initiated with both supported samples. When supported on alumina, cobalt nitrate reduction is catalysed with the two events that occur below $350{ }^{\circ} \mathrm{C}$ happening at lower temperatures, while reduction above $350{ }^{\circ} \mathrm{C}$ is moved to higher temperatures. The silica-supported complex in contrast exhibits reduction events that are all reduced in temperature relative to the unsupported salt. However, there is evidence of the formation of cobalt silicate with a high temperature reduction. The study has
\end{abstract}

S. David Jackson

david.jackson@glasgow.ac.uk

1 Centre for Catalysis Research, WestCHEM, School of Chemistry, University of Glasgow, Glasgow G12 8QQ, Scotland, UK shown that the calcination and direct reduction of supported cobalt nitrate is significantly affected by the support and that different conditions are required to achieve the same state.

Keywords Cobalt nitrate $\cdot$ Reduction $\cdot$ Oxidation $\cdot$ Silica . Alumina

\section{Introduction}

Research into cobalt catalysts is an area of importance to industry due to their extensive application in a range of industrial processes, most notably Fischer-Tropsch synthesis $[1,2]$. The preparation of cobalt catalysts typically involves impregnation, where a solution of a cobalt salt is brought into contact with a catalyst support such as silica or alumina. The water is removed by drying followed by calcination in air to give the oxide and then the reduction of the oxide to metal. On occasion direct reduction from the salt to the metal is employed. During these processes the metal salt and the support can interact modifying the behaviour of the material to any subsequent process.

There is a huge amount of literature available in the scientific press citing the characterisation of cobalt catalysts. There have been many studies examining the structural, chemical as well as electronic properties of these catalysts. These results have been obtained using a combination of different methods, the majority of which make use of techniques such as temperature-programmed reduction and oxidation (TPO/TPR), transmission electron microscopy (TEM), X-ray diffraction (XRD), thermo gravimetric analysis and differential scanning calorimetry (TGA-DSC) [3-7]. It has been well documented that the different preparation variables influence the structure and 
Table 1 BET surfaces areas, average pore diameters and pore volumes for the supports and prepared catalysts

\begin{tabular}{lccc}
\hline Sample & $\begin{array}{l}\text { Surface area } \\
\left(\mathrm{m}^{2} \mathrm{~g}^{-1}\right)\end{array}$ & Average pore diameter $(\AA)$ & Pore volume $\left(\mathrm{cm}^{3} \mathrm{~g}^{-1}\right)$ \\
\hline Silica support & 148 & 203 & 0.75 \\
Co/silica & 59 & 182 & - \\
Alumina support & 205 & 155 & 0.79 \\
Co/alumina & 132 & 127 & 0.42 \\
\hline
\end{tabular}

Fig. 1 TGA weight and derivative weight profiles for cobalt nitrate in $2 \%$ oxygen/ argon
Fig. 2 TGA/DSC of cobalt nitrate in $2 \% \mathrm{O}_{2} / \mathrm{Ar}$
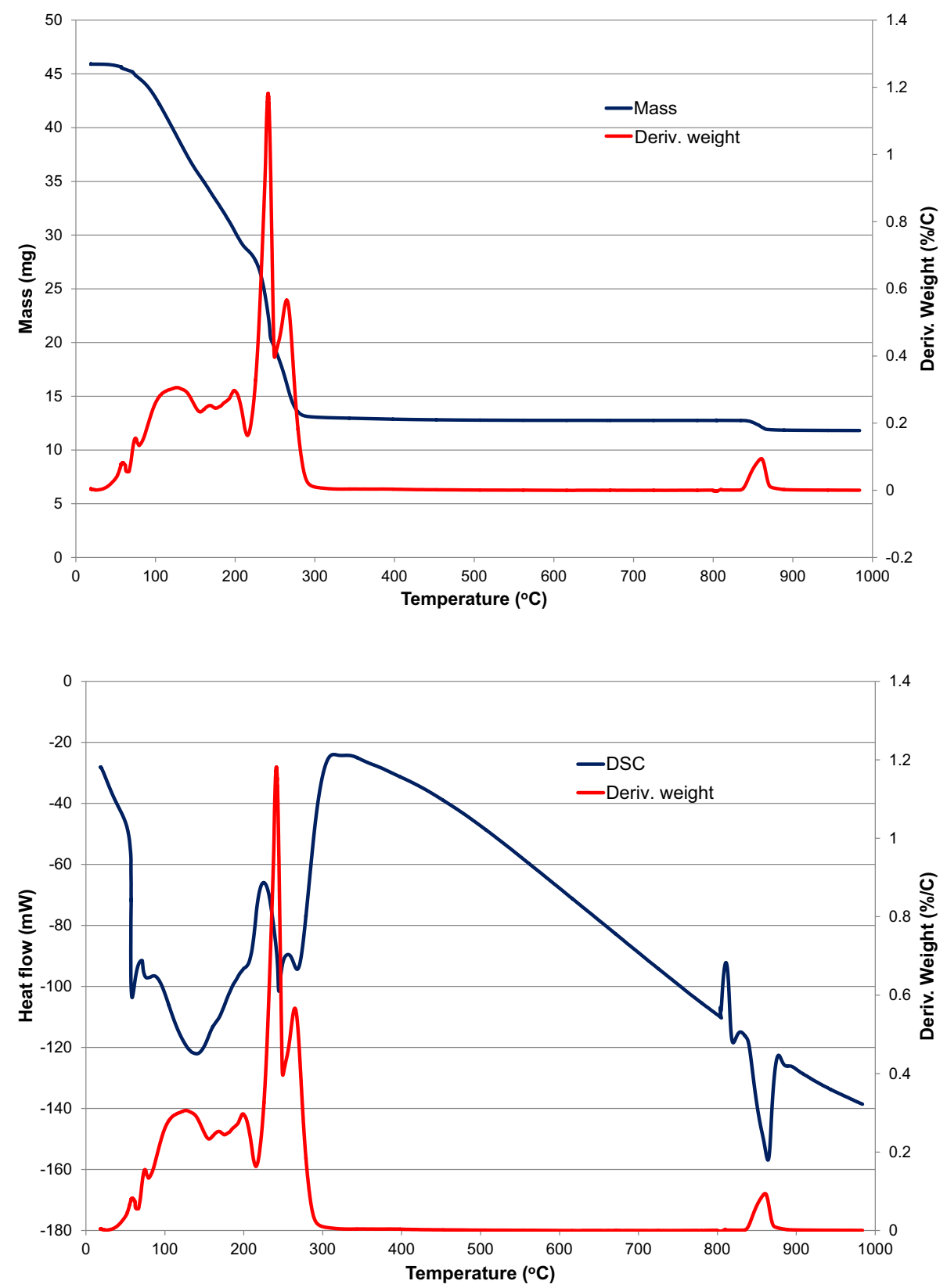

morphology of catalysts. The support provides mechanical strength and thermal stability to the cobalt nanoparticles, while facilitating a high cobalt dispersion. A variety of supports are used to prepare cobalt catalysts depending on the properties required; however, the bulk of the literature is concerned with high surface area oxide supports, in particular silica, alumina and titania supported cobalt catalysts [3-7]. The use of supports such as zeolites [8] and 
carbon [9] has also been reported in the literature. There have been many studies into the interaction between the support and the cobalt species. This is due to the fact that the interaction between cobalt species and support can affect the response of cobalt to reduction as well as dispersion [10]. The choice of the oxide support largely determines the number of active cobalt metal sites stabilised after reduction as well as the percentage of cobalt oxides that can be reduced to cobalt metal. This is due to a difference in the Co-support oxide interaction. A strong Co-support oxide interaction, as occurs in the case of alumina and titania, stabilises small clusters therefore favouring dispersion, but at the same time decreases their reducibility. On the contrary, a much weaker interaction leading to higher reducibility occurs for the silica-supported cobalt catalysts. In this case the cobalt particles tend to appear as large clusters on the support surface, which results in a relatively low cobalt dispersion [11-13].

It has also been shown that the pore structure of the supports has a significant effect on the cobalt particles produced [5]. Using a variety of techniques, Storsæter and co-workers investigated the effect the support had on the size, appearance and shape of cobalt particles [12]. They reported that the cobalt oxide crystallite size was found to increase with increasing pore diameter of support. Similar effects have been observed for cobalt catalysts supported on silicas with increasing mean pore diameters [14].

The general objectives of this research were to investigate the effect of the support and the gas atmosphere on the decomposition and reduction of cobalt nitrate hexahydrate supported on silica and alumina to gain a greater understanding of the calcination and reduction procedures used in catalyst manufacturing processes. A $20 \%$ weight loading was chosen as this is typical loading for a Fischer-Tropsch catalyst but it also ensures that any changes can be easily detected.

\section{Experimental}

Catalysts containing $20 \mathrm{wt} \%$ cobalt were prepared by incipient wetness of alumina (Engelhard Al-3992) and silica (Degussa Aerosil 200) supports with aqueous solutions of cobalt nitrate hexahydrate $\left\{\mathrm{Co}\left(\mathrm{NO}_{3}\right)_{2} \cdot 6 \mathrm{H}_{2} \mathrm{O}\right\}$. Prior to impregnation, the supports were dried in an oven at $100{ }^{\circ} \mathrm{C}$ overnight. To ensure uniform metal dispersion on the support, the precursor salt was dissolved in a volume of water equal to the support pore volume. For both supports used it was found that the pore volume was around $1 \mathrm{~cm}^{3} \mathrm{~g}^{-1}$. The resulting materials were mixed in a rotary evaporator for $1 \mathrm{~h}$ before any excess water was slowly removed by increasing the temperature to $80{ }^{\circ} \mathrm{C}$ for $30 \mathrm{~min}$. Both samples were dried in an oven at $100{ }^{\circ} \mathrm{C}$ overnight.

The catalysts were characterised under three different gas atmospheres: an argon gas atmosphere, a $2 \%$ v/v oxygen/ argon gas atmosphere and a 5\% v/v hydrogen/nitrogen gas atmosphere. The oxygen treatment reveals the behaviour that can be expected during calcination of the catalyst precursor, while the 5\% hydrogen/nitrogen gas atmosphere would be typical of direct reduction of the catalysts.

Thermo-gravimetric analysis (TGA) was performed on all catalysts using a combined TGA/DSC SDT Q600 thermal analyser coupled to an ESS mass spectrometer for evolved gas analysis. Samples were heated from 30 to $1000{ }^{\circ} \mathrm{C}$ using a heating ramp of $10{ }^{\circ} \mathrm{C} \mathrm{min}^{-1}$ at a flow rate of $100 \mathrm{ml} \mathrm{min}{ }^{-1}$. For mass spectrometric analysis,
Fig. 3 TGA/MS of $\mathrm{Co}\left(\mathrm{NO}_{3}\right)_{2} \cdot 6 \mathrm{H}_{2} \mathrm{O}$ in $2 \% \mathrm{O}_{2} / \mathrm{Ar}$

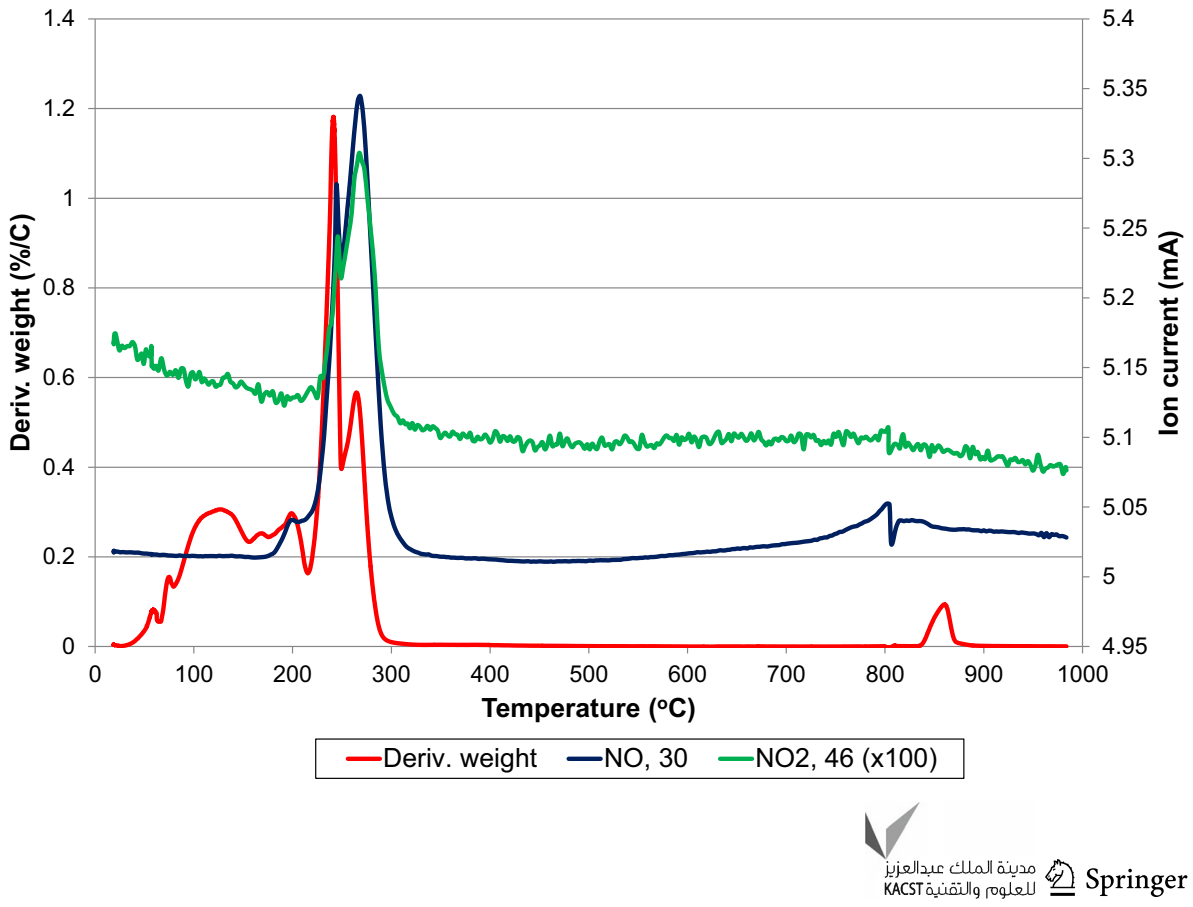


mass fragments with $m / z=2,14,16,17,18,28,30,32$, 40, 44 and 46 were followed.

To determine the BET surface area, samples were outgassed at $110{ }^{\circ} \mathrm{C}$ in flowing nitrogen before measurements were performed using a Micromeritics Gemini III 2375 Surface Area Analyzer.

\section{Results}

The surface area of the supports and catalysts were determined by BET analysis (Table 1). Although showing some variation, the results show that the supports had very similar physical properties with comparable surface areas, pore diameters and pore volumes. The addition of the cobalt precursor to the supports resulted in a decrease in the overall catalyst surface area.

\section{Cobalt nitrate hexahydrate}

To be able to determine the influence of the supports cobalt nitrate was analysed by TGA/DSC in the absence of the supports. The TGA and DSC are shown in Figs. 1 and 2. The TGA reveals a significant weight loss between 100 and $300{ }^{\circ} \mathrm{C}$ and a further small weight loss at $\sim 860{ }^{\circ} \mathrm{C}$. During these weight loss events, water, nitrogen monoxide,
Fig. 4 TGA weight and derivative weight profiles of cobalt nitrate in 5\% hydrogen/ nitrogen

Fig. 5 TGA-DSC profiles of cobalt nitrate in 5\% hydrogen/ nitrogen
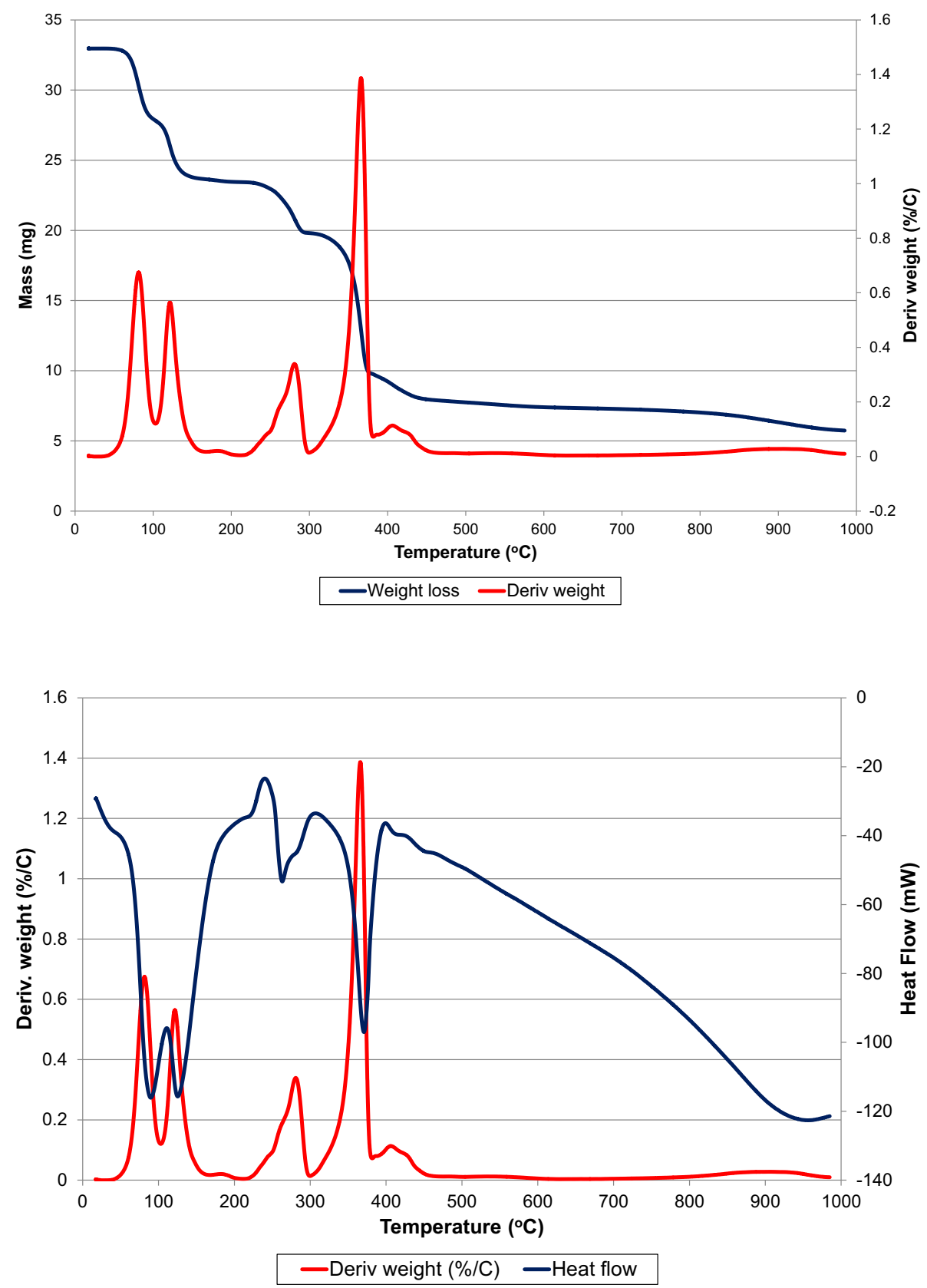
nitrogen dioxide and oxygen are the major gaseous products released (Fig. 3). From the DSC the initial endothermic event at $58{ }^{\circ} \mathrm{C}$ can be attributed to the melting of the cobalt nitrate [15]. Indeed all the weight loss events are endothermic with two endothermic decomposition events at 244 and $268{ }^{\circ} \mathrm{C}$ corresponding to the evolution of $\mathrm{NO}$ and trace levels of $\mathrm{NO}_{2}$. Apart from the high-temperature weight loss, the decomposition in oxygen is complete by $325^{\circ} \mathrm{C}$. Analysis of the weight loss at $350{ }^{\circ} \mathrm{C}$ confirms the conversion of $\mathrm{Co}\left(\mathrm{NO}_{3}\right)_{2} \cdot 6 \mathrm{H}_{2} \mathrm{O}$ to $\mathrm{Co}_{3} \mathrm{O}_{4}$ in agreement with the literature [16]. The weight loss around $862{ }^{\circ} \mathrm{C}$ is attributed to formation of $\mathrm{CoO}$ from the decomposition of the cobalt spinel, $\mathrm{Co}_{3} \mathrm{O}_{4}$. In keeping with this an evolution of oxygen also occurs at this temperature and the overall measured weight loss $(74 \%)$ is identical to the theoretical weight loss expected for the decomposition of fully hydrated $\mathrm{Co}\left(\mathrm{NO}_{3}\right)_{2} \cdot 6 \mathrm{H}_{2} \mathrm{O}$ complex to $\mathrm{CoO}$. This suggests a stepwise decomposition of $\mathrm{Co}\left(\mathrm{NO}_{3}\right)_{2} \cdot 6 \mathrm{H}_{2} \mathrm{O}$ to $\mathrm{Co}_{3} \mathrm{O}_{4}$ followed by decomposition of $\mathrm{Co}_{3} \mathrm{O}_{4}$ to $\mathrm{CoO}$ at high temperature. The presence of a low concentration of oxygen in the feed gas is insufficient to stop the thermodynamically driven conversion of $\mathrm{Co}_{3} \mathrm{O}_{4}$ to $\mathrm{CoO}$. This behaviour is in general agreement with the literature, Fischer and coworkers [15] found two main decomposition events at 235 and $255{ }^{\circ} \mathrm{C}$ for $\mathrm{Co}\left(\mathrm{NO}_{3}\right)_{2} \cdot 6 \mathrm{H}_{2} \mathrm{O}$ with the evolution of water and nitrogen dioxide, respectively; however, they did not observe any NO formation, whereas in our system NO is the major decomposition product. As Figueras had used
Fig. 6 Mass spectrometric analysis for NO $(\mathrm{m} / \mathrm{z}=30)$ and $\mathrm{NO}_{2}(m / z=46)$ for cobalt nitrate decomposition in 5\% hydrogen/nitrogen
Fig. 7 TGA of $\mathrm{Co}\left(\mathrm{NO}_{3}\right)_{2} \cdot 6 \mathrm{H}_{2} \mathrm{O}$ supported on alumina in $2 \%$ oxygen/argon
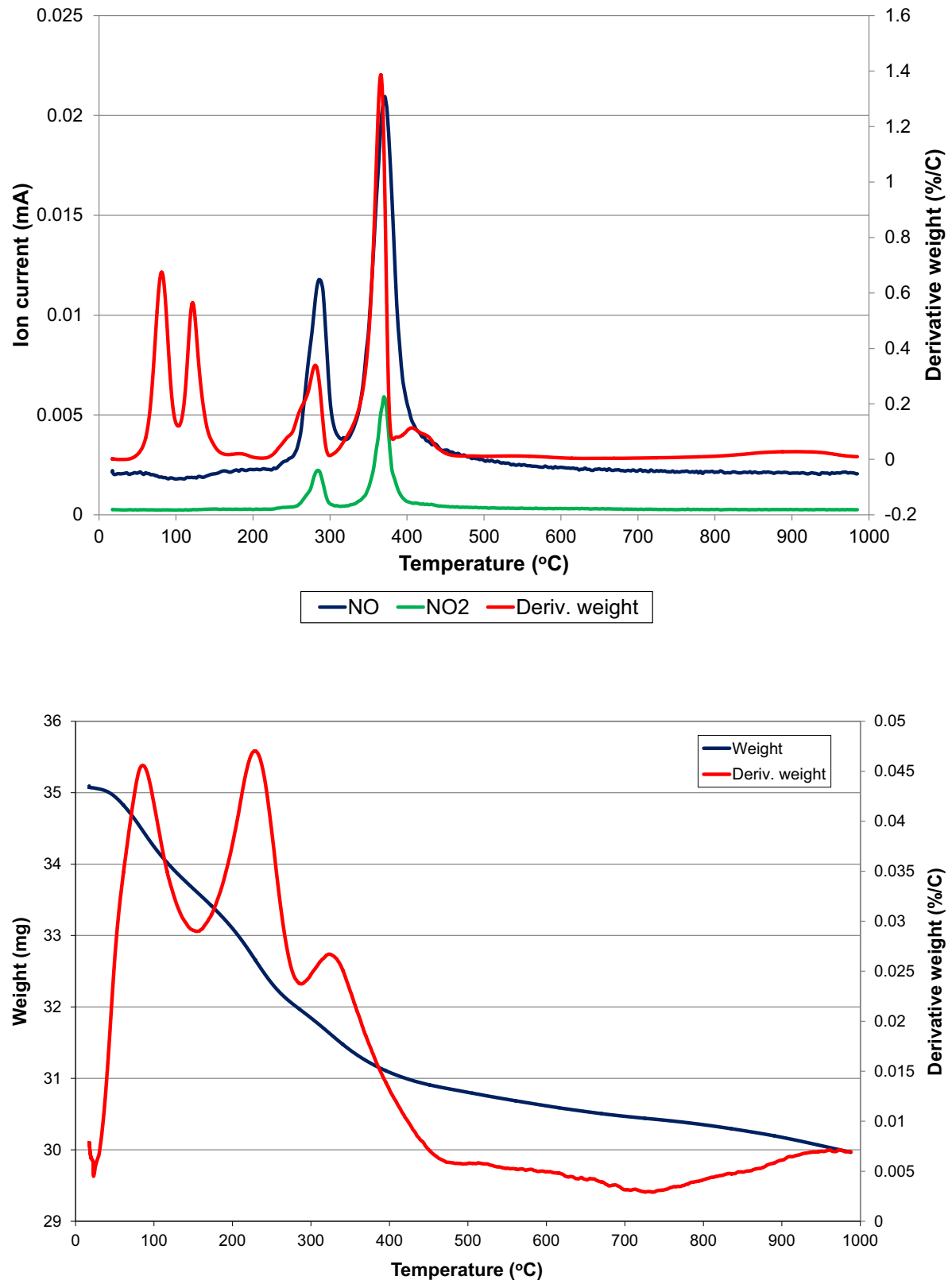
nitrogen [15], we repeated our TGA/MS using argon rather than $2 \%$ oxygen/argon but once again we obtained NO as our major eluant. Hence the decomposition of cobalt nitrate hexahydrate below $350{ }^{\circ} \mathrm{C}$ can be better described by the following equation:

$3\left[\mathrm{Co}\left(\mathrm{NO}_{3}\right)_{2} \cdot 6 \mathrm{H}_{2} \mathrm{O}\right] \rightarrow \mathrm{Co}_{3} \mathrm{O}_{4}+6 \mathrm{NO}+18 \mathrm{H}_{2} \mathrm{O}+4 \mathrm{O}_{2}$

However, the decomposition is not as simple as the above equation suggests. The small evolution of NO below $200{ }^{\circ} \mathrm{C}$ has been assigned [17] to the initial decomposition of dehydrated $\mathrm{Co}\left(\mathrm{NO}_{3}\right)_{2}$ to give a mixture of materials including $\mathrm{CoO}$ and $\mathrm{Co}_{2} \mathrm{O}_{3}$ before the main decomposition event which leads to the formation of $\mathrm{Co}_{3} \mathrm{O}_{4}$.
The decomposition of cobalt nitrate hexahydrate in a hydrogen flow was also studied by TGA/DSC/MS. From the weight and derivative weight profiles shown in Fig. 4 the reduction of cobalt nitrate appears complex with around seven weight loss events at $80,120,280,365,400$ and $420{ }^{\circ} \mathrm{C}$. From the DSC profile in Fig. 5 it is clear that weight losses below $400{ }^{\circ} \mathrm{C}$ are endothermic events. There is a suggestion that the weight loss events $\sim 400{ }^{\circ} \mathrm{C}$ are exothermic. Mass spectroscopic analysis confirms that the first two weight losses are solely due to loss of water. The weight losses at 280 and $365^{\circ} \mathrm{C}$ are accompanied by the evolution of water, nitrogen monoxide and nitrogen dioxide (Fig. 6) and the uptake of hydrogen.
Fig. 8 TGA/DSC of $\mathrm{Co}\left(\mathrm{NO}_{3}\right)_{2} \cdot 6 \mathrm{H}_{2} \mathrm{O}$ supported on alumina in $2 \%$ oxygen/argon
Fig. 9 TGA/MS profiles in $2 \%$ oxygen/argon of evolved gases from $\mathrm{Co}\left(\mathrm{NO}_{3}\right)_{2} \cdot 6 \mathrm{H}_{2} \mathrm{O}$ supported on alumina (trace levels of $\mathrm{NO}_{2}$ seen at first NO peak)
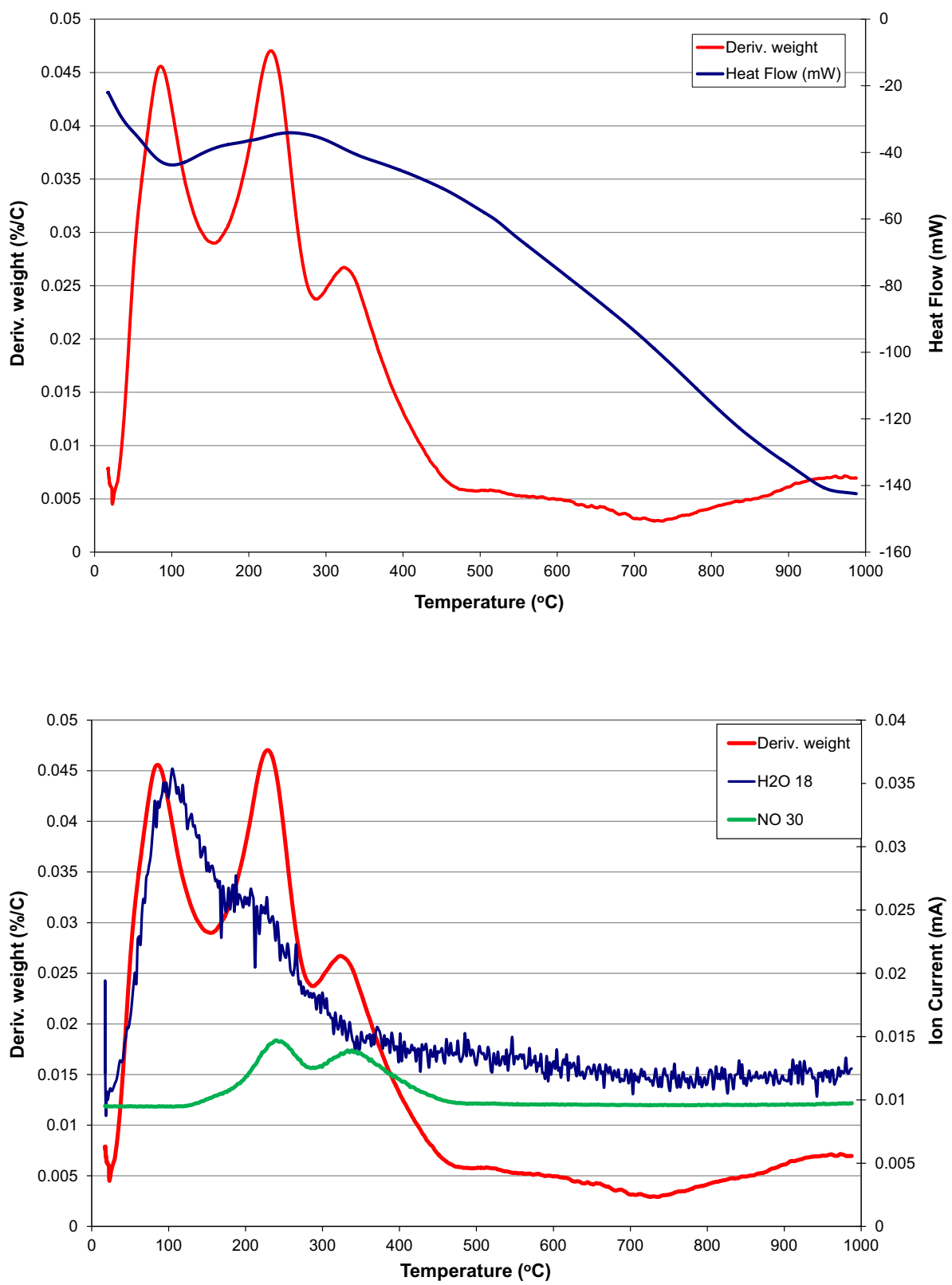
The first two weight loss events are shown to be loss of water from mass spectroscopy (not shown). There is no associated hydrogen up-take and so it can be assigned to loss of water of hydration. The first weight loss is equivalent to the loss of 2.5 waters of hydration while the second weight loss is equivalent to the loss of two waters of hydration. Therefore, by $200{ }^{\circ} \mathrm{C}$ the cobalt nitrate has only on average 1.5 waters of hydration. The subsequent events are not in complete agreement with the literature. Rosynek and Polansky [4] examined the reduction of cobalt nitrate and observed two events at 280 and $370{ }^{\circ} \mathrm{C}$, which is in good agreement with our data. However, although they detected NO evolution for the first event they did not detect $\mathrm{NO}$ for the second event and assigned it to reduction of
$\mathrm{CoO}$, whereas we observe significant $\mathrm{NO} / \mathrm{NO}_{2}$ evolution as well as water evolution for both events. It is not clear why there is this difference although the heating rate used by Rosynek and Polansky [4] was twice that used in this study and it is possible that at the higher heating rate the second NO evolution is unresolved and is seen as a single event. Lapidus et al. [3] also examined direct reduction of cobalt nitrate and observed two events at 230 and $317^{\circ} \mathrm{C}$ with a heating rate of $24^{\circ} \mathrm{min}^{-1}$. They ascribed the first event to cobalt nitrate decomposition and the second event to cobalt oxide reduction. Nevertheless, both our weight loss events have the evolution of $\mathrm{NO} / \mathrm{NO}_{2}$ indicating that the second reduction is not the reduction of $\mathrm{CoO}$ to $\mathrm{Co}$ but rather is a reduction of a second form of cobalt nitrate, possibly
Fig. 10 TGA of $\mathrm{Co}\left(\mathrm{NO}_{3}\right)_{2} \cdot 6 \mathrm{H}_{2} \mathrm{O}$ supported on alumina in 5\% hydrogen/ nitrogen
Fig. 11 DSC of $\mathrm{Co}\left(\mathrm{NO}_{3}\right)_{2} \cdot 6 \mathrm{H}_{2} \mathrm{O}$ supported on alumina in 5\% hydrogen/ nitrogen
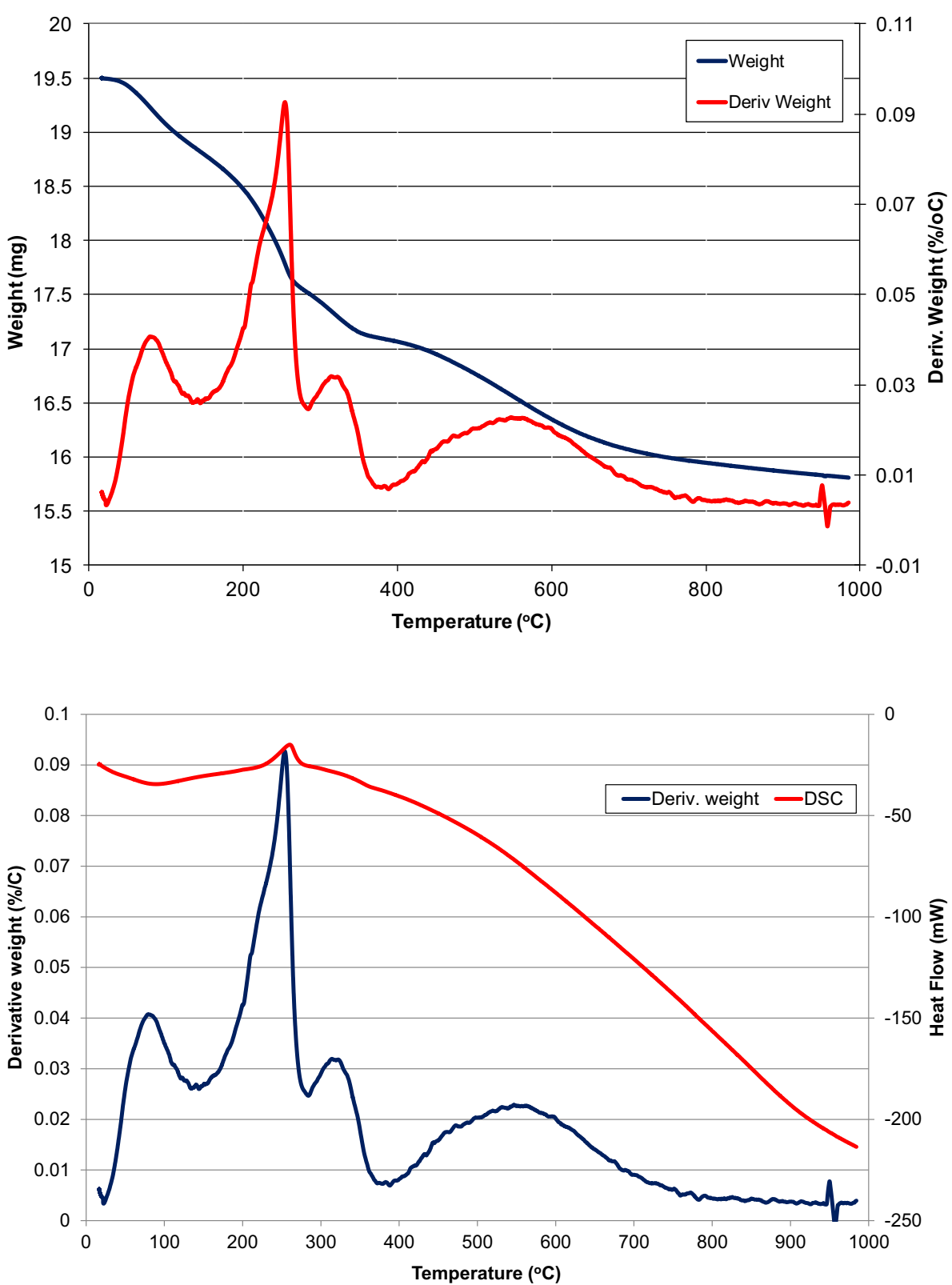
differing in the extent of hydration. Total reduction to metal is not achieved at $500{ }^{\circ} \mathrm{C}$ where there is still significant oxygen associated with the cobalt (approximately $\mathrm{CoO}_{0.5}$ ); indeed full reduction is not achieved until around $850{ }^{\circ} \mathrm{C}$.

Cobalt nitrate was impregnated onto both silica and alumina supports as described in the experimental section. Each sample was then studied by TGA/DSC/MS under oxidising and reducing conditions.

\section{Cobalt nitrate hexahydrate/alumina}

The TGA for the alumina sample heated in oxygen/argon is shown in Fig. 7, while the associated TGA/DSC is shown in Fig. 8. The heat flux of the catalyst as measured by the DSC has less fine structure than that of the cobalt nitrate in the absence of the support because the support can act as a heat sink masking exothermic and endothermic events. The TGA/ MS is shown in Fig. 9. The evolution of water at $105^{\circ} \mathrm{C}$ is associated with an endotherm and is principally desorption of physisorbed water from the catalyst support. There is then subsequent water production and concurrent $\mathrm{NO}$ evolution with trace levels of $\mathrm{NO}_{2}$ at $237^{\circ} \mathrm{C}$. Finally there is production of $\mathrm{NO}$ at $335{ }^{\circ} \mathrm{C}$. It is noticeable that as per the unsupported compound there are two evolutions of NO; however, although the first evolution occurs at approximately the same temperature as that found for the complex, the second evolution from the catalyst occurs $\sim 70{ }^{\circ} \mathrm{C}$ higher than that found with the pure compound. This suggests that there are two types of cobalt nitrate on the surface of the alumina, one
Fig. 12 Water evolution and hydrogen up-take from TGA of $\mathrm{Co}\left(\mathrm{NO}_{3}\right)_{2} \cdot 6 \mathrm{H}_{2} \mathrm{O} /$ alumina in $5 \%$ hydrogen/nitrogen

Fig. 13 Nitrogen oxides evolution from TGA of $\mathrm{Co}\left(\mathrm{NO}_{3}\right)_{2} \cdot 6 \mathrm{H}_{2} \mathrm{O}$ /alumina in $5 \%$ $\mathrm{H}_{2} / \mathrm{N}_{2}$
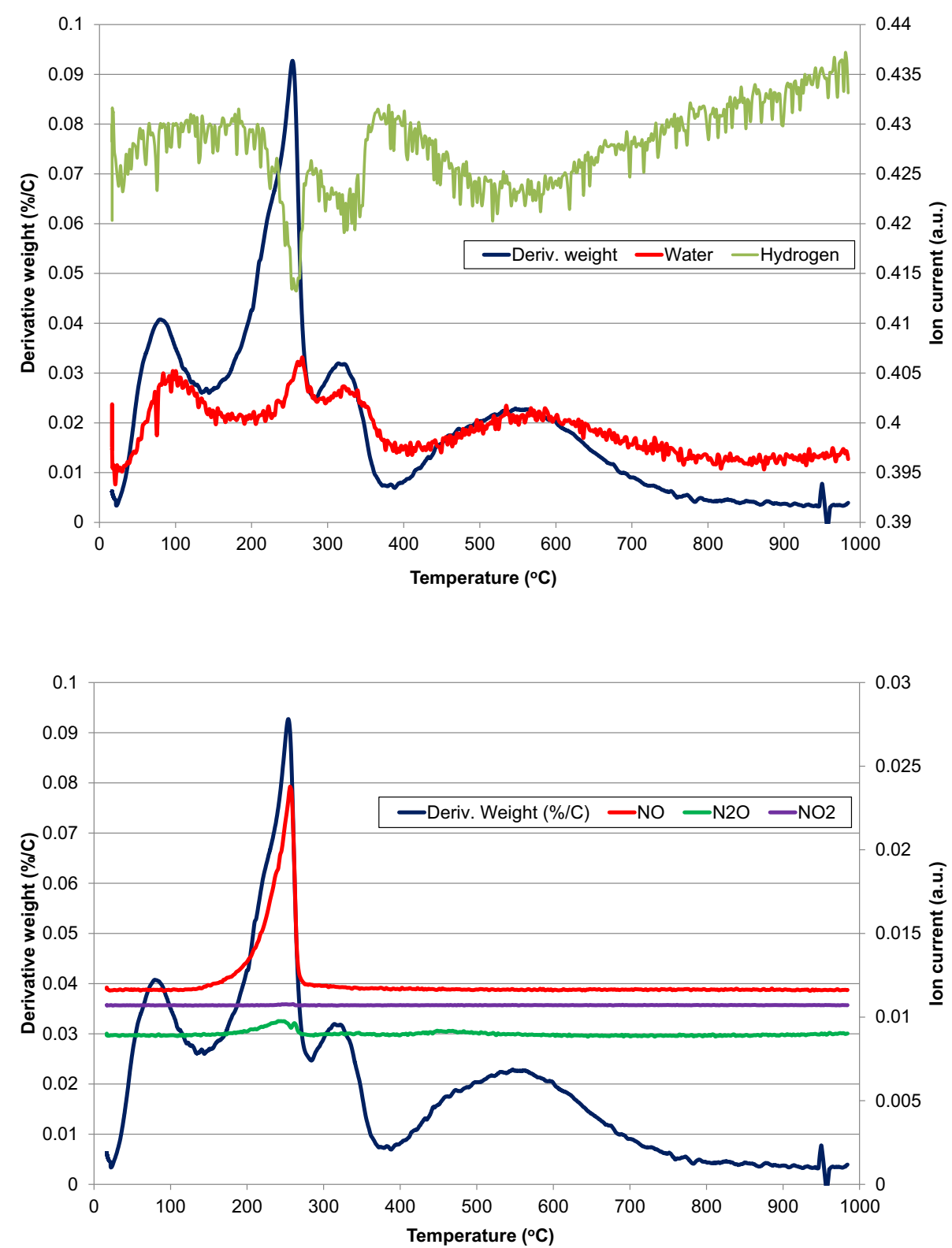
which has little interaction and another that has a stabilising interaction. This stabilising effect is also seen at high temperature as there is no obvious conversion of $\mathrm{Co}_{3} \mathrm{O}_{4}$ to $\mathrm{CoO}$ around $860{ }^{\circ} \mathrm{C}$ that is observed in the absence of the support. This is supported by a study of catalyst impregnation by Kordulis and co-workers, [18] who used Raman spectroscopy to detect $\mathrm{Co}_{3} \mathrm{O}_{4}$ and $\mathrm{CoAl}_{2} \mathrm{O}_{4}$, but not $\mathrm{CoO}$, after calcination at $850{ }^{\circ} \mathrm{C}$.

The TGA and DSC for the alumina sample heated in hydrogen/argon are shown in Figs. 10 and 11 . The associated TGA/MS are shown in Figs. 12 and 13. There are a series of weight losses at $80,223,254,317$ and $553{ }^{\circ} \mathrm{C}$. The weight loss at $80{ }^{\circ} \mathrm{C}$ is endothermic and is related to the loss of weakly bound water from the catalyst. The weight loss at $223{ }^{\circ} \mathrm{C}$ is endothermic and is associated with the loss of NO from the sample indicating the initiation of decomposition of the cobalt nitrate. While this process is occurring a second event initiates shown by the weight loss at $254{ }^{\circ} \mathrm{C}$, this second event is exothermic and is associated with the loss of water, $\mathrm{NO}, \mathrm{N}_{2} \mathrm{O}$ and $\mathrm{NO}_{2}$ (trace) and the up-take of hydrogen. This behaviour is different from that of cobalt nitrate in the absence of the alumina. With the unsupported material the decomposition of cobalt nitrate started at $280{ }^{\circ} \mathrm{C}$ and then was followed with further decomposition at $365{ }^{\circ} \mathrm{C}$; both of these events were accompanied by the evolution of water, nitrogen monoxide and nitrogen dioxide. With the supported material the initiation of the decomposition of the cobalt nitrate is reduced by $\sim 60{ }^{\circ} \mathrm{C}$ and once decomposition is initiated the reduction process rapidly starts. The weight loss event at $254{ }^{\circ} \mathrm{C}$ is reduction of cobalt species formed from
Fig. 14 TGA of $\mathrm{Co}\left(\mathrm{NO}_{3}\right)_{2} \cdot 6 \mathrm{H}_{2} \mathrm{O}$ supported on silica in $2 \%$ oxygen/argon
Fig. 15 TGA/DSC of $\mathrm{Co}\left(\mathrm{NO}_{3}\right)_{2} \cdot 6 \mathrm{H}_{2} \mathrm{O}$ supported on silica in $2 \%$ oxygen/argon
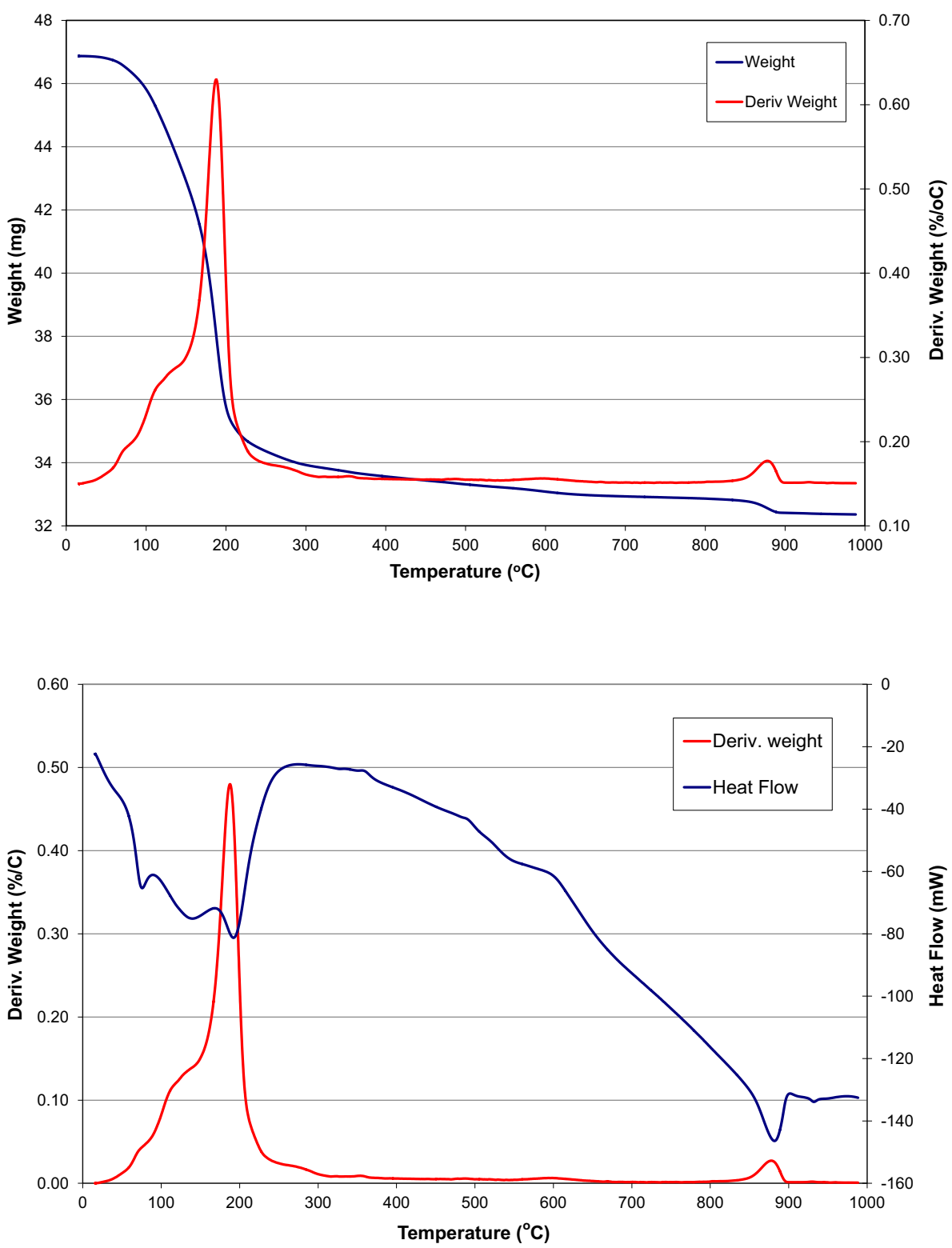
partial decomposition and may involve the reduction of the nitrate.

$\mathrm{Co}\left(\mathrm{NO}_{3}\right)_{2}+3 \mathrm{H}_{2} \rightarrow \mathrm{CoO}+2 \mathrm{NO}+3 \mathrm{H}_{2} \mathrm{O}$

However, $\mathrm{N}_{2} \mathrm{O}$ is also formed and, as shall be discussed below, $\mathrm{Co}_{3} \mathrm{O}_{4}$. Therefore, it is likely that there is further reaction between cobalt oxide and $\mathrm{NO}$ to give the cobalt spinel and $\mathrm{N}_{2} \mathrm{O}$ :

$3 \mathrm{CoO}+2 \mathrm{NO} \rightarrow \mathrm{Co}_{3} \mathrm{O}_{4}+\mathrm{N}_{2} \mathrm{O}$

The weight loss at $317^{\circ} \mathrm{C}$ is associated with the uptake of hydrogen and the evolution of water. No nitrogen oxides were observed. Typically cobalt oxide spinel $\left(\mathrm{Co}_{3} \mathrm{O}_{4}\right)$ reduces in two steps [19], $\mathrm{Co}^{3+}$ to $\mathrm{Co}^{2+}$ and then $\mathrm{Co}^{2+}$ to Co metal as per the following equations:
$\mathrm{Co}_{3} \mathrm{O}_{4}+\mathrm{H}_{2} \rightarrow 3 \mathrm{CoO}+\mathrm{H}_{2} \mathrm{O}$

$\mathrm{CoO}+\mathrm{H}_{2} \rightarrow \mathrm{Co}+\mathrm{H}_{2} \mathrm{O}$

giving a ratio of hydrogen up-takes of 1:3. Examination of the hydrogen up-take related to the weight loss events at 317 and $553{ }^{\circ} \mathrm{C}$ reveals a 1:3 ratio, suggesting that the reduction at $317{ }^{\circ} \mathrm{C}$ is associated with the reduction of $\mathrm{Co}^{3+}$ to $\mathrm{Co}^{2+}$ and the reduction at $553{ }^{\circ} \mathrm{C}$ with the reduction of $\mathrm{Co}^{2+}$ to cobalt metal, which is in agreement with the results of Borg et al. [5] and a hot-stage XRD study [20]. This is a marked change from the values obtained with the unsupported salt. The $\mathrm{Co}^{3+}$ to $\mathrm{Co}^{2+}$ reduction temperature has been reduced by $\sim 80{ }^{\circ} \mathrm{C}$ from 400 to $317^{\circ} \mathrm{C}$, while the $\mathrm{Co}^{2+}$ to cobalt metal reduction has increased in temperature by $\sim 130{ }^{\circ} \mathrm{C}$ from 420 to
Fig. 16 Evolved gas from TGA of $\mathrm{Co}\left(\mathrm{NO}_{3}\right)_{2} \cdot 6 \mathrm{H}_{2} \mathrm{O}$ supported on silica in $2 \%$ oxygen/argon
Fig. 17 TGA of $\mathrm{Co}\left(\mathrm{NO}_{3}\right)_{2} \cdot 6 \mathrm{H}_{2} \mathrm{O}$ supported on silica in $5 \%$ hydrogen/nitrogen
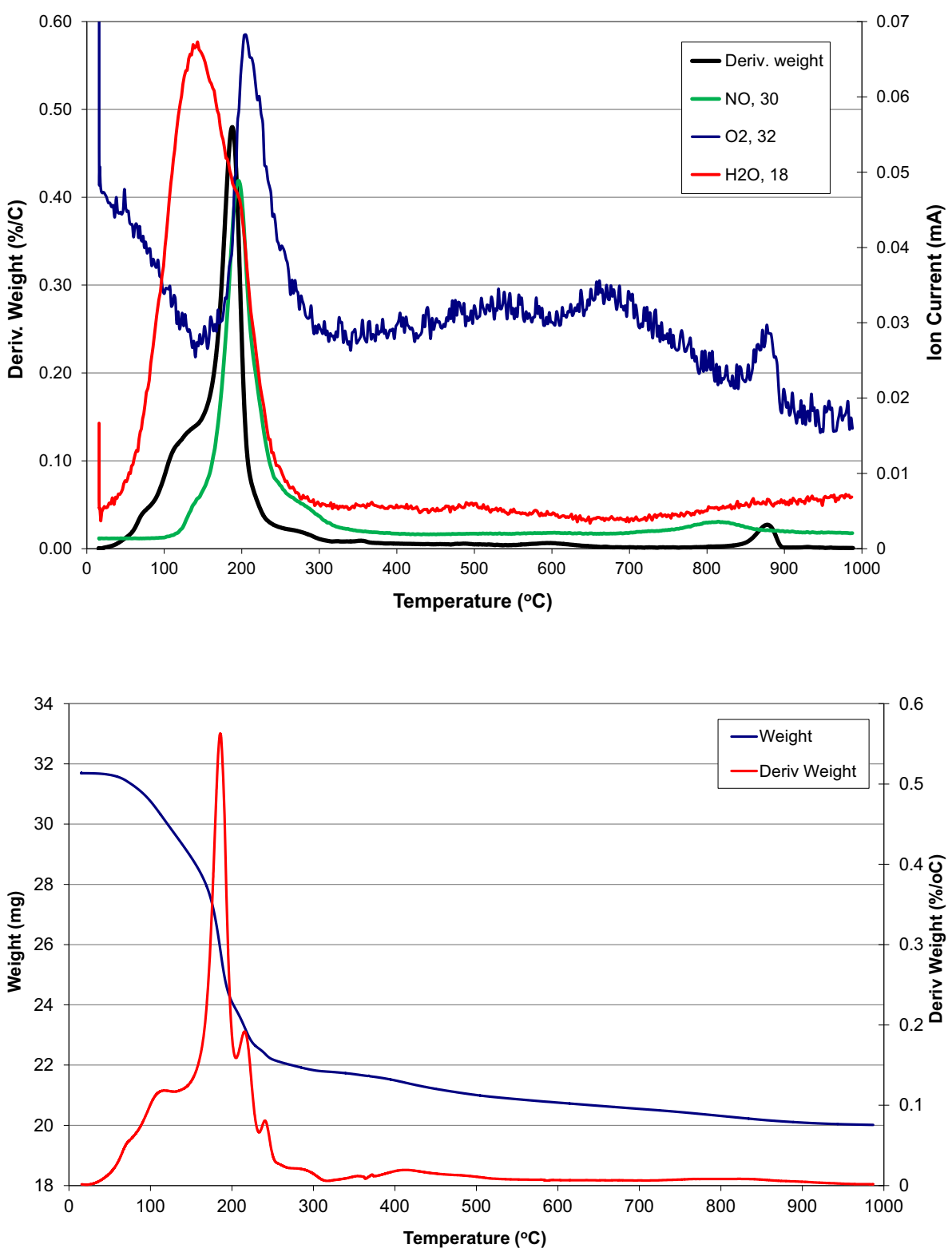
$553{ }^{\circ} \mathrm{C}$. This stabilising effect could be the result of the formation of cobalt aluminate $\left(\mathrm{CoAl}_{2} \mathrm{O}_{4}\right)$, which is known to reduce $\sim 500{ }^{\circ} \mathrm{C}[21]$.

\section{Cobalt nitrate hexahydrate/silica}

The TGA for cobalt nitrate hexahydrate supported on silica heated in $2 \%$ oxygen/argon is shown in Fig. 14. There are four obvious weight loss events at $75,130,186$ and $878{ }^{\circ} \mathrm{C}$. The DSC profile shown in Fig. 15 reveals that all of these events are endothermic; however, the profile also shows three small exothermic events at 356,489 and $590{ }^{\circ} \mathrm{C}$.

Analysis of the evolved gas by MS during the TGA in $2 \%$ oxygen/argon is shown in Fig. 16. The first weight losses at 75 and $130{ }^{\circ} \mathrm{C}$ can be assigned to the loss of water, which can come from both the cobalt nitrate and the silica support. The weight loss at $186{ }^{\circ} \mathrm{C}$ is the main decomposition of cobalt nitrate with the evolution of water, $\mathrm{NO}$ and $\mathrm{O}_{2}$ :

$3\left[\mathrm{Co}\left(\mathrm{NO}_{3}\right)_{2} \cdot 6 \mathrm{H}_{2} \mathrm{O}\right] \rightarrow \mathrm{Co}_{3} \mathrm{O}_{4}+6 \mathrm{NO}+18 \mathrm{H}_{2} \mathrm{O}+4 \mathrm{O}_{2}$

Therefore, the silica support catalyses the decomposition of cobalt nitrate as the temperature at which the decomposition occurs has been reduced by $\sim 60{ }^{\circ} \mathrm{C}$ relative to the unsupported cobalt nitrate. This is in contrast to the alumina support which stabilised the system (Figs. 123 ) and required higher temperatures to facilitate the decomposition. The opposite effect is seen with the high-temperature weight loss related to the
Fig. 18 TGA/DSC of $\mathrm{Co}\left(\mathrm{NO}_{3}\right)_{2} \cdot 6 \mathrm{H}_{2} \mathrm{O}$ supported on silica in 5\% hydrogen/nitrogen
Fig. 19 Water evolution and hydrogen up-take from TGA of $\mathrm{Co}\left(\mathrm{NO}_{3}\right)_{2} \cdot 6 \mathrm{H}_{2} \mathrm{O} /$ silica in $5 \%$ hydrogen/nitrogen
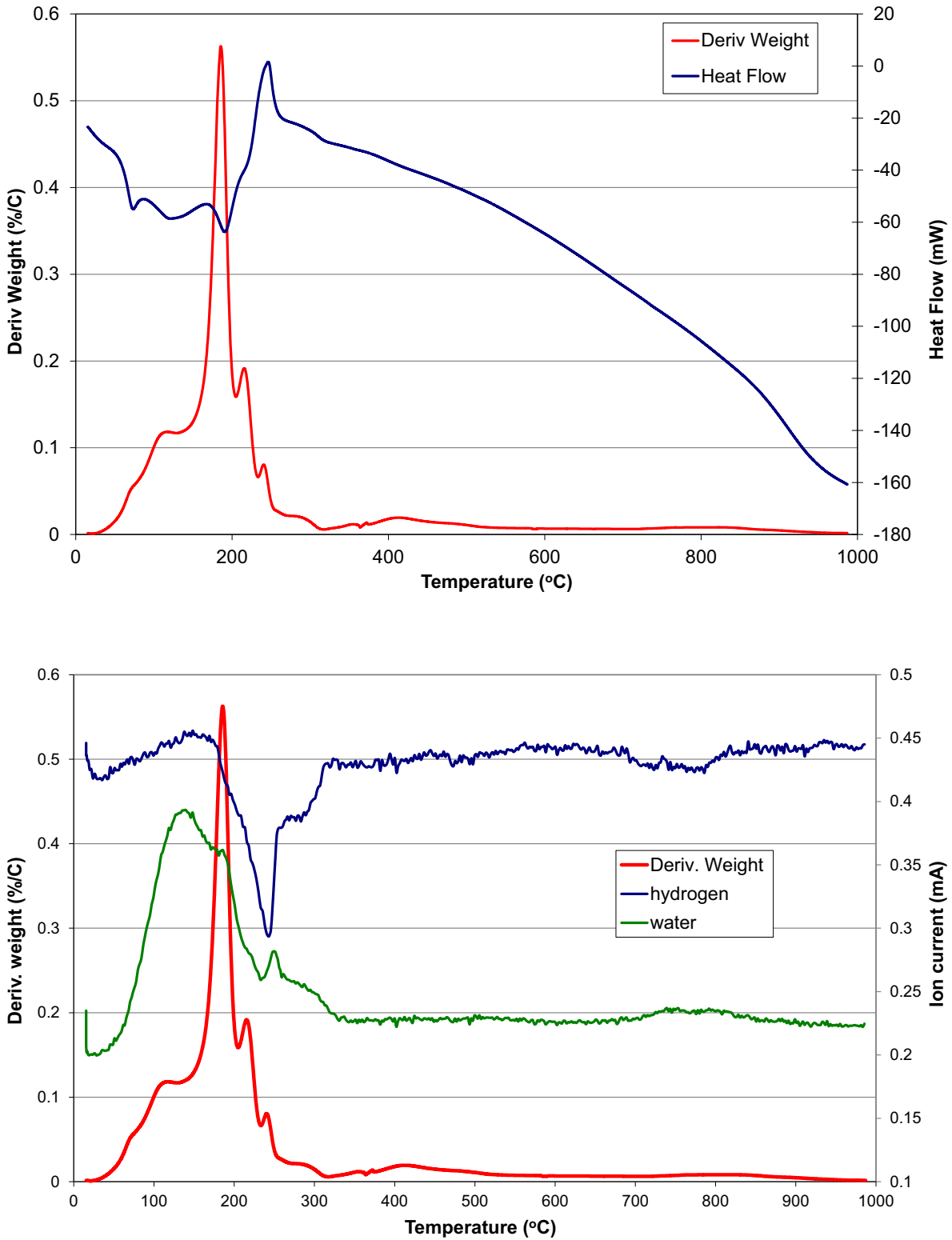
Fig. 20 Nitrogen oxides evolution from TGA of $\mathrm{Co}\left(\mathrm{NO}_{3}\right)_{2} \cdot 6 \mathrm{H}_{2} \mathrm{O} /$ silica in $5 \%$ $\mathrm{H}_{2} / \mathrm{N}_{2}$

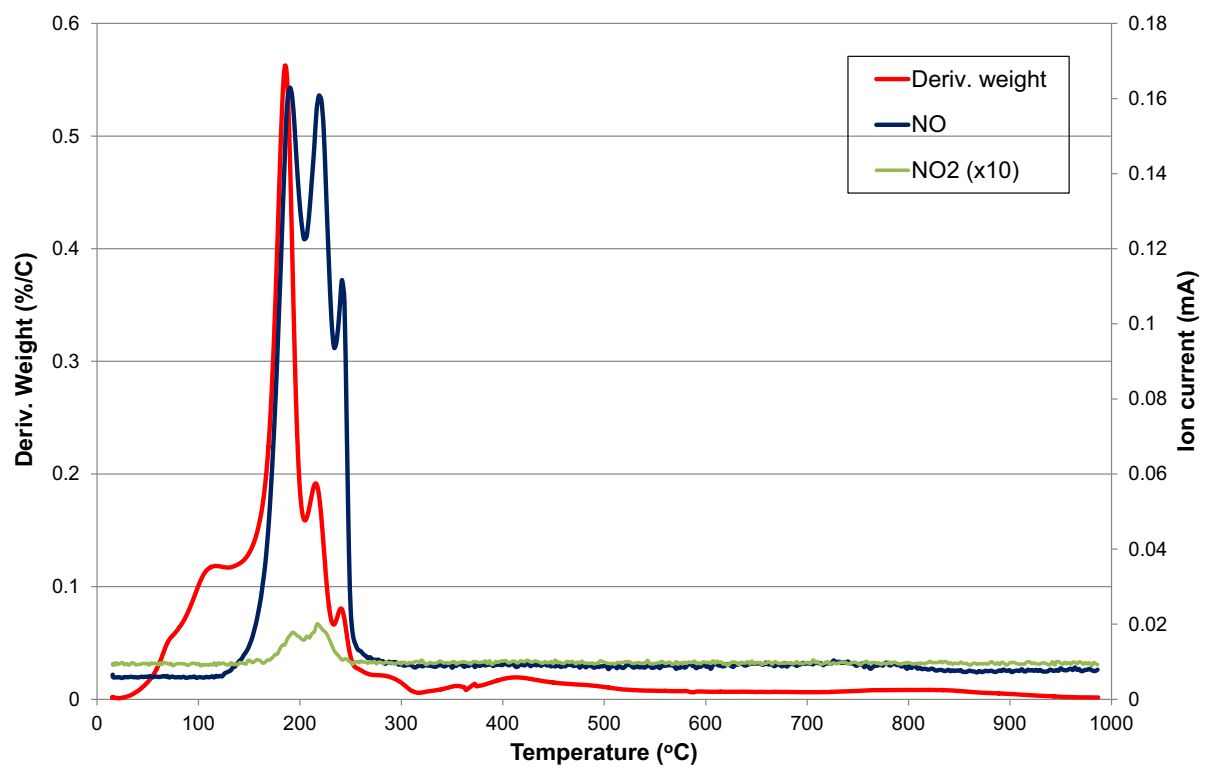

supported, whereas the alumina support stabilises $\mathrm{Co}^{2+}$ resulting in a significant increase in reduction temperature. This stabilisation by alumina may reflect a stronger interaction between alumina and cobalt and possible formation of $\mathrm{CoAl}_{2} \mathrm{O}_{4}$.

The high-temperature mass loss $\left(795^{\circ} \mathrm{C}\right)$ shows hydrogen up-take and water production. This mass loss is likely to be related to the reduction of cobalt silicate $\left(\mathrm{CoSiO}_{3}\right)$. A study by Puskas et al. [22] revealed that cobalt silicate can be formed in situ during the direct reduction of cobalt nitrate supported on silica facilitated by the water produced during reduction. However, Coulter and Sault [23] indicated that cobalt silicate is formed during the drying stage although they agree that water is a key component. Therefore, it is possible that cobalt silicate is formed during the reduction process; however, its extent will be limited due to the high space velocity (low residence time) minimising water partial pressure and time in the reactor.

\section{Conclusions}

The decomposition/reduction behaviour of cobalt nitrate hexahydrate supported alumina and silica has been studied in two gas atmospheres. In an oxygen/argon atmosphere the decomposition is generally simplified in comparison with the unsupported salt with fewer weight loss events. When supported on alumina, cobalt nitrate is stabilised with decomposition events shifted to higher temperatures, whereas when supported on silica cobalt nitrate is destabilised with only one significant decomposition event, which occurs at a lower temperature. In a hydrogen/nitrogen atmosphere partial decomposition of cobalt nitrate same temperature for the pure complex and the silica 
occurs before reduction is initiated over both supports. When supported on alumina, cobalt nitrate reduction is catalysed with the two events below $350{ }^{\circ} \mathrm{C}$ happening at lower temperatures, while the reduction that takes place above $350{ }^{\circ} \mathrm{C}$ is pushed to higher temperatures. In contrast, the silica-supported complex exhibits reduction events that are all reduced in temperature relative to the unsupported salt. However, there is evidence of the formation of cobalt silicate with a high-temperature reduction. The study has shown that the calcination and direct reduction of supported cobalt nitrate is significantly affected by the support and that different conditions are required to achieve the same state.

Open Access This article is distributed under the terms of the Creative Commons Attribution 4.0 International License (http:// creativecommons.org/licenses/by/4.0/), which permits unrestricted use, distribution, and reproduction in any medium, provided you give appropriate credit to the original author(s) and the source, provide a link to the Creative Commons license, and indicate if changes were made.

\section{References}

1. Richard LA, Moreau P, Rugmini S, Daly F (2013) FischerTropsch performance correlated to catalyst structure: trends in activity and stability for a silica-supported cobalt catalyst. Appl Catal A 464-465:200-206

2. Fischer N, van Steen E, Claeys M (2013) Structure sensitivity of the Fischer-Tropsch activity and selectivity on alumina supported cobalt catalysts. J Catal 299:67-80

3. Lapidus A, Krylova A, Kazanskii V, Borovkov V, Zaitsev A, Rathousky J, Zukal A, Jancalkova M (1991) Hydrocarbon synthesis from carbon monoxide and hydrogen on impregnated cobalt catalysts Part I. Physico-chemical properties of $10 \%$ cobalt/alumina and $10 \%$ cobalt/silica. Appl Catal 73:65-82

4. Rosynek MP, Polansky CA (1991) Effect of cobalt source on the reduction properties of silica-supported cobalt catalysts. Appl Catal 73:97-112

5. Borg O, Eri S, Blekkan EA, Storsæter S, Wigum H, Rytter E, Holmen A (2007) Fischer-Tropsch synthesis over $\gamma$-aluminasupported cobalt catalysts: effect of support variables. J Catal 248:89-100

6. Chu W, Chernavskii PA, Gengembre L, Pankina GA, Fongarland PA, Khodakov AY (2007) Cobalt species in promoted cobalt alumina-supported Fischer-Tropsch catalysts. J Catal 252:215-230

7. Sun S, Fujimoto K, Yoneyama Y, Tsubaki N (2002) FischerTropsch synthesis using $\mathrm{Co} / \mathrm{SiO}_{2}$ catalysts prepared from mixed precursors and addition effect of noble metals. Fuel $81: 1583-1591$

8. Concepción P, López C, Martínez A, Puntes VF (2004) Characterization and catalytic properties of cobalt supported on delaminated ITQ-6 and ITQ-2 zeolites for the Fischer-Tropsch synthesis reaction. J Catal 228:321-327

9. Raróg-Pilecka W, Miśkiewicz E, Matyszek M, Kaszkur Z, Kępiński L, Kowalczyk Z (2006) Carbon-supported cobalt catalyst for ammonia synthesis: effect of preparation procedure. J Catal 237:207-210

10. Riva R, Miessner H, Vitali R, Del Piero G (2000) Metal-support interaction in $\mathrm{Co} / \mathrm{SiO}_{2}$ and $\mathrm{Co} / \mathrm{TiO}_{2}$. Appl Catal A 196:111-123

11. Voß M, Borgmann D, Welder G (2002) Characterization of alumina, silica, and titania supported cobalt catalysts. J Catal 212:10-21

12. Storsæter S, Tøtdal B, Walmsley JC, Tanem BS, Holmen A (2005) Characterization of alumina-, silica-, and titania-supported cobalt Fischer-Tropsch catalysts. J Catal 236:139-152

13. Jacobs G, Das TK, Zhang Y, Li J, Racoillet G, Davis BH (2002) Fischer-Tropsch synthesis: support, loading, and promoter effects on the reducibility of cobalt catalysts. Appl Catal A 233:263-281

14. Saib AM, Claeys M, van Steen E (2002) Silica supported cobalt Fischer-Tropsch catalysts: effect of pore diameter of support. Catal Today 71:395-402

15. Cseri T, Bekassy S, Kenessey G, Liptay G, Figueras F (1996) Characterization of metal nitrates and clay supported metal nitrates by thermal analysis. Thermochimica Acta 288:137-154

16. Mehandjiev D, Nikolova-Zhecheva E (1980) Mechanism of the decomposition of cobaltous compounds in vacuo. Thermochimica Acta 37:145-154

17. Seham A, Mansour A (1994) Spectrothermal studies on the decomposition course of cobalt oxysalts Part II. Cobalt nitrate hexahydrate. Mater Chem Phys 36:317-323

18. Zacharaki I, Kontoyannis CG, Boghosian S, Lycourghiotis A, Kordulis Ch (2009) Cobalt oxide supported on alumina catalysts prepared by various methods for use in catalytic afterburner of PEM fuel cell. Catal Today 143:38-44

19. Jacobs G, Ji Y, Davis BH, Cronauer D, Kropf AJ, Marshall CL (2007) Fischer-Tropsch synthesis: Temperature programmed EXAFS/XANES investigation of the influence of support type, cobalt loading, and noble metal promoter addition to the reduction behavior of cobalt oxide particles. Appl Catal A 333:177-191

20. Wigzell FA, MSc. Dissertation (2007) The characterisation of supported cobalt catalysts. University of Glasgow

21. Chung KS, Massoth FE (1980) Studies on molybdena-alumina catalysts: VII. Effect of cobalt on catalyst states and reducibility. J Catal 64:320-331

22. Puskas I, Fleisch TH, Full PR, Kaduk JA, Marshall CL, Meyers BL (2006) Novel aspects of the physical chemistry of $\mathrm{Co} / \mathrm{SiO}_{2}$ Fischer-Tropsch catalyst preparations: the chemistry of cobalt silicate formation during catalyst preparation or hydrogenation. Appl Catal A 311:146-154

23. Coulter KE, Sault AG (1995) Effects of activation on the surface properties of silica-supported cobalt catalysts. J Catal 154:56-64 